\title{
Erzurum Bölgesinde Yetişen Betula pendula Yapraklarının Antioksidan Kapasitelerinin Belirlenmesi ve Kemometrik Karakterizasyonu
}

\author{
Onur ŞENOL ${ }^{1 *}$ \\ ${ }^{1}$ Atatürk Üniversitesi, Eczacılık Fakültesi, Analitik Kimya Anabilim Dalı, 25240, ERZURUM
}

\section{Öz}

Bu çalışmada, Erzurum bölgesinin karakteristik bitki örtüsü içerisinde yer alan Huş Ağacına ait farklı yerleşimlerden alınan yaprak örnekleri farklı in vitro antioksidan kapasite yöntemleri ile incelenmiş ve kemometrik karakterizasyonu yapılmıştır. Uzundere, Horasan ve Şenkaya bölgelerinde mayıs-temmuz aralığında toplanan örnekler kurutulmuş ve etanol ekstreleri çıkarılmıştır. Bakır II iyonu İndirgeyici Antioksidan Kapasite (CUPRAC), Demir III iyonu İndirgeyici Antioksidan Kapasite (FRAP) ve Difenil pikril Hidrazin (DPPH) yöntemleri için gerçekleştirilen analizlere bütün örnekler pozitif yanıt vermişlerdir. En yüksek antioksidan kapasite değerlerine Şenkaya bölgesinden elde edilen örneklerle ulaşılmıştır. Elde edilen değerler bilgisayar algoritmaları yardımıyla kemometrik olarak incelendiğinde; sonuçların anlamlı farklılık gösterdiği ve her bölgede rakım değişimiyle pozitif korelasyon gösteren farklılıklar tespit edilmiştir. Yapılan çalışma vasıtasıyla antioksidan kapasite değerleri ile coğrafi karakterizasyonun gerçekleştirilebileceği ve rakımsal farklılıkların Huş ağacı yapraklarının fenolik ve flavanoid içeriğine anlamlı etki yaptığı sonucuna varılmıştır. Huş ağacı bitkisinin antioksidan kapasitesi sebebiyle özellikle kanser ve kozmetik gibi önemli alanlarda kullanılabileceği düşünülmektedir.

Anahtar Kelimeler: Antioksidan Kapasite, Huş Ağacı Yaprağı, CUPRAC, FRAP, DPPH.

\section{Determination of Antioxidant Activity and Chemometric Characterization of Betula pendula Leaves in Erzurum Region}

\begin{abstract}
In this study, leaf samples of Birch Tree collected from different settlements in the characteristic vegetation of Erzurum region were investigated with different in vitro antioxidant activity investigated and chemometrics characterization was carried out. The samples were harvested in the May-July period from Uzundere, Horasan and Şenkaya regions, dried and their ethanol extracts were obtained. CUPRAC, FRAP and DPPH responses were positive for all samples. The highest antioxidant capacity values were obtained from samples of Şenkaya region. When the obtained values are examined chemometrically with the help of computer algorithms; significant differences and a positive correlation with the altitude change in each region were obtained. It was concluded that geographic characterization can be realized by antioxidant activity values and the altitude differences have a significant effect on phenolic and flavanoid contents of birch leaves. Owing to the antioxidant activity of the birch plant it is thought that it can be used especially in important areas such as cancer and cosmetics.
\end{abstract}

Keywords: Antioxidant Activity, Birch Tree Leaf, CUPRAC, FRAP, DPPH. 


\section{Giriş}

Dış enerji orbitallerinde bir veya birden fazla ortaklanmamış elektron içeren organik veya inorganik moleküllere serbest radikaller ismi verilir (Codoñer-Franch vd., 2011). Serbest radikaller kararsız ve yüksek tepkime potansiyeline sahip bileşiklerdir. Enzim reaksiyonları, otooksidasyon reaksiyonları, yaşamsal faaliyetler gibi endojen kaynaklı olabildiği gibi hava kirliliği, sigara dumanı, iyonize 1şınlar, Ultra Viyole (UV) radyasyonu ve ksenobiyotikler gibi farklı çevresel değişkenlerin etkisi ile de oluşabilmektedirler (Doğmuş ve Durucasu, 2013). Bu bileşikler organizmada nükleik asitler, karbonhidratlar, lipitler gibi pek çok biyolojik metabolitle farklı zincir reaksiyonlara sebep olmaktadır (Güner vd., 2014). Serbest radikaller organizmada biyokimyasal tepkimelerin yan ürünü olarak ortaya çıkar; makrofajlarda bakterilerin ortadan kaldırılması, elektron transfer tepkimeleri ve biyosinyal üretim metabolizması gibi birçok yolakta görev alırlar. Bu kararsız bileşiklerin canlı hücrelerinde aşırı oranlarda bulunması yaşlanma, nörolojik rahatsızlıklar, kardiyovasküler problemler ve kanser gibi rahatsızlıklara yol açmaktadır (Bursal vd., 2013).

Serbest radikallerin oluşturduğu hasarları ortadan kaldırmak için canlı organizmalar çeşitli antioksidan savunma sistemleri geliştirmiştir (Velioğlu, 2000). Oksijenin ve kararsız radikallerin oksidatif tesirlerinden ortadan kaldırmak için bütün aerobik organizmaların barındırdı̆̆ı sistemlere antioksidan savunma sistemleri denir(Pacifici ve Davies, 1991). Genel olarak bakıldığında; Antioksidan savunma sistemleri singlet oksijeni bağlayarak, metallerin katalizlediği oksidasyon reaksiyonlarını engeller veya serbest radikallerin neden olduğu reaksiyonu durdurarak kapasite gösterirler (Velioğlu, 2000). Reaktif oksijen türlerinin tehlikeli etkilerini yok eden veya azaltan bileşikler antioksidanlardır (Sarıkürkcü vd., 2016).

Doğal olarak insan vücudunda üretilen ve besinlerden de alınarak üretilen antioksidan maddelerin, hastalıklara sebebiyet verdiği düşünülen serbest radikallerin ve Reaktif Oksijen Türlerinin (ROS) zararlı, tehlikeli etkilerine karşı önemli rolleri vardır.İnsan vücudunda doğal olarak üretilen antioksidanların koruyucu etkileri sınırlı olup ROS oluşumunun biyolojik sistemlerdeki antioksidan kapasiteyi aşması halinde oksidatif stres oluşmaktadır. Son yıllarda yapılan çalışmalar sonucu; hava kirliliği, hazır gıda tüketiminde artış, stres, sigara gibi tütün ürünlerinin kullanımı nedenlerine bağlı olarak vücutta serbest radikal oluşumunda artış görülmüştür. Antioksidan bileşikler oluşan bu serbest radikallere karşı etkili ve güçlü bileşiklerdir. Vücudumuzda var olan oksidan-antioksidan dengenin bozulması sonucu özellikle günümüzde oksidatif stres ile ilişkili hastalıklar konusunda artış yaşanmıştır (Moller vd., 1996; Bonina vd., 2008; Bono vd., 2015; Calderon-Garciduenas, 2016). Bitkilerle yapılan çalışmalar bitkilerin iyi bir antioksidan kaynağı olduğunu göstermektedir (Duthie vd., 2000). Antioksidanlar daha çok kırmızı ve yeşil yapraklı bitkilerde mevcuttur. Ayrıca çoğu vitaminler; A, C, E vitaminleri doğal antioksidan özellik göstermektedir.

Gıdalar genel olarak; polifenoller, flavonlar, likopenler, flavonoidler, kateşin, amigdalin, gallik, vanilik, karotenoidler gibi antioksidanların birini veya birden fazla kısmını içermektedir(Shetty et al., 2013). Polifenoller ikiye ayrılırlar. Bunlar; fenolik asitler ve flavonoidlerdir. Hidroksibenzoik asit ve hidroksisinnamik asit grupları fenolik asit grubuna aittir. Flavanoidler ise altı gruba ayrılmaktadır. Bunlar; flavonoller, isoflavanoitler, flavanoller, flavanonlar, antosiyanidinler ve flavonlar şeklindedir (D Archivio vd., 2007).

Betula cinsi yaklaşık 50 farklı alt türe sahiptir ve kuzey yarım kürede yetişmektedir(Atkinson, 1992). Bu türler içinde ticari olarak en çok kullanılan tür Betula pendula'dır (Pääkkönen vd, 1997). Huş ağacı yapraklarının Mirsetin, kersetin glikozidleri ve farklı flavanoidleri içerdiği pek çok çalışmada belirtilmiştir(Pawłowska, 1983; Wagner vd., 1983; Keinänen ve Julkunen-Tiitto, 1998).

Çalışmamızda Betula cinsi ağaçlardan olan ve ülkemizde 'Huş ağacı' olarak bilinen Betula pendula cinsi ağaçların yapraklarında antioksidan kapasite tayini yapılması ve coğrafi farklılıkların kemometrik olarak açıklanması amaçlanmıştır.

\section{Materyal ve Metod}

Çalışmada üç farklı antioksidan kapasite yöntemi Erzurum Uzundere (1140 m), Horasan (1540 m) ve Şenkaya (1850 m) yörelerinden alınan Betula pendula yaprak örneklerine uygulanmıştır. Örnekler Atatürk Üniversitesi Eczacılık Fakültesi herbaryumunda saklanmaktadır (Uzundere; AUEF1356, Horasan; AUEF1357, Şenkaya; AUEF1358). Mayıs-Temmuz döneminde toplanan örnekler yıkanarak temizlenip kurulmuştur. Kurutma nemsiz havadar bir ortamda direk güneş almayan bir odada gerçekleştirilmiştir. Örnekler öncelikle oda sıcaklığında 36 saat boyunca etanolde maserasyona birakılmıştır. Daha sonra örnekler mantolu ısıtıcıda geri çeviren soğutucu altında $45^{\circ} \mathrm{C}$ 'de etanol ile ekstre edilmiştir. Ekstraksiyon işlemi üç defa tekrarlanmıştır. Süzüntü rotavapor 
yardımıyla kurutulup etanolde derişimi ayarlanmıştır. Her bölgeden 5 farklı örnek hazırlanıp antioksidan kapasite analizleri gerçekleştirilmiştir. Referans standart madde olarak gallik asit (Merck, Germany) kullanılmıştır. Spektrofotometre yöntemiyle elde edilen veriler daha sonra MATLAB programına aktarılarak kemometrik karakterizasyonları gerçekleştirilmiştir.

CUPRAC reaktifini hazırlamak için önce 0.4262 gram CuCI2.2H2O tartılıp, $250 \mathrm{~mL}$ deiyonize içerisinde çözüldü $(10 \mathrm{mM})$. Sonra asetat tamponu oluşturmak üzere 19.27 gram Amonyum Asetat bileşiği $250 \mathrm{~mL}$ su içerisinde hazırlandı. $7.5 \mathrm{mM}$ derişiminde neokuproin çözeltisi $25 \mathrm{~mL}$ 'lik balon jojede 0.039 gram Neokuproin bileşiğinin \%96 saflıkta etanol ile karıştırılmasıyla elde edildi. Daha sonra ise $60 \mu \mathrm{L}$ asetat tamponu, $60 \mu \mathrm{L}$ bakır (II) klorür, $60 \mu \mathrm{L}$ neocuproin çözeltisi ve $66 \mu \mathrm{L}$ numuneden oluşan çözelti hazırlanmıştır. Örnekler 30 dakika boyunca inkübe edildi ve sonra $450 \mathrm{~nm}$ dalga boyunda ölçüm sonuçları alındı. Bu yöntem $\mathrm{Cu}$ (II) Neocuproin kompleksinin ortamda bulunan antioksidan etki gösteren bileşikler aracılığıyla $\mathrm{Cu}$ (I) Neocuproin'e dönüşmesi ve bu oluşan kompleksinde $450 \mathrm{~nm}$ dalga boyunda verdiği absorbansa dayanmaktadır.

Frap yöntemi direkt bir antioksidan kapasite belirleme tekniğidir. Bu yönüyle inhibisyon temelli antioksidan tayin yöntemlerine göre daha kesin ve hassas sonuçlar elde edilmesini sağlar. Bu yöntemde inhibisyon yerine oluşan kompleksin miktarıyla orantılı olarak absorbans değeri artar. Bu yüzden FRAP ile CUPRAC yöntemlerinin korelasyonu diğer yöntemlere nazaran daha yüksektir. FRAP numunesi hazırlayabilmek için öncelikle $10 \mathrm{mM}$ TPTZ çözeltisi içerisinde $40 \mathrm{mM} \mathrm{HCl}$ asit içerecek şekilde $100 \mathrm{~mL}$ balon jojeye alındı ve hacim saf su ile $100 \mathrm{~mL}$ 'ye tamamlandı. Başka bir kapta $20 \mathrm{mM} \mathrm{FeCl} 3$ çözeltisi hazırlandı. Üçüncü bir kapta ise $\mathrm{pH}$ 3.6'da 0.3 M sodyum asetat içeren bir tampon çözelti hazırlandı. Bu üç çözeltiden eşit hacimlerde alınarak $30 \mathrm{~mL}$ 'lik FRAP çözeltisi elde edildi. Daha sonra bu çözeltiden $285 \mu \mathrm{L}$ pleytlere aktarıldı ve her bir çözeltinin üzerine $15 \mu \mathrm{L}$ örnek ilave edildi. 30 dakikalık inkübasyon aşamasının ardından çözeltiler $593 \mathrm{~nm}$ dalga boyunda ölçüldü.

Bu yöntemde difenil-1 pikril hidrazil isimli radikale karşı örneklerin göstermiş olduğu yanıt antioksidan kapasite ölçümleri için kullanılır. Bu madde az sayıdaki stabilitesi yüksek ve maliyeti uygun azot radikallerinden olup $515 \mathrm{~nm}$ dalga boyunda absorbans vermektedir. İndirgenme reaksiyonu sürecinde DPPH çözeltisi rengini kaybeder ve renk şiddetinde meydana gelen azalma spektrofotometrede kolay bir şekilde ölçümü yapılmasını mümkün kılar. DPPH yöntemi yakından incelendiğinde; orijinal DPPH prosedürüne göre $390 \mu \mathrm{L}$ ve $25 \mathrm{mg} / \mathrm{L}$ derişimindeki DPPH ç̧özeltisi metanol içerisinde hazırlanır ve $10 \mu \mathrm{L}$ hacmindeki örnek çözeltisi ile karıştııılır. Absorbans değeri stabil kalıncaya dek hazırlanan final çözelti spektrofotometre cihazında $515 \mathrm{~nm}$ dalga boyunda ölçülür. Bu ölçüm bazı örneklerde 30 dakikaya kadar çıkabilmektedir. Tepkimeye girmeyen \% DPPH miktarı aşağıdaki formülle saptanır:

$\%$ DPPH $=($ DPPHkalan/DPPHilk eklenen $) \times 100$

DPPH yüzdesi ile antioksidan madde derişimi arasında bir korelasyon mevcuttur.

Kemometrik analizleri gerçekleştirebilmek için yöntem çıktıları MATLAB programına aktarılmıştır. Aktarılan ölçümlerin varyans değerleri hesaplanarak skorlanmış ve matris çözümlemeleri vasıtasıyla grafiğe aktarılmıştır. Kemometri temel olarak kimyasal işlemler sonucu elde edilen verilerin istatistiksel olarak değerlendirilmesidir. Çoklu değişkenli veri analizleri işlenir ve kemometrik algoritmalar vasıtasıyla yorumlanır. Varyans analizini gerçekleştirebilmek için alınan örneklerin antioksidan kapasite değerleri PLS-Toolbox adı verilen yazılıma işlenmiş ve Ortogonal Partial Least Square (OPLS) algoritmasına göre değerlendirilmiş̧ir. Her bir değer Y bloğu üzerine aktarılmış olup X bloğu ise 1 ve 0 değerleri ile kodlanmıştır.

\section{Bulgular ve Tartışma}

\subsection{CUPRAC Yöntemi}

Kontrol numunesi olarak Gallik asit kullanılmıştır. Farklı olan her bir derişimde 6 farklı Gallik asit numunesi alındı ve bu numunelerin absorbansları okunmuştur. Derişime karşı absorbans grafiğginin lineer olduğu 1-50 $\mu \mathrm{g} / \mathrm{mL}$ çalışma aralığının kalibrasyon eğrisi türetilmiş (Şekil 1) ve istatistiksel hesaplamaları yapılmıı̧tır (Tablo 1). Daha sonra ise Huş ağacı yaprak örnekleri aynı yöntem kullanılarak ölçülmüştür. Gallik asit eşdeğer antioksidan kapasiteleri her bir örnek için hesaplanmıştır. Ortalama eşdeğer gallik asit miktarları ise Tablo 2'de verilmiştir. 
Tablo 1. Kalibrasyon eğrisinin istatistiki değerleri

\begin{tabular}{cccccc}
\hline Yöntem & $\begin{array}{c}\text { ÇA } \\
(\mu \mathbf{g} / \mathbf{m L})\end{array}$ & $\mathbf{L R}^{\mathbf{a}}$ & $\mathbf{S a}$ & $\mathbf{S b}$ & $\mathbf{R}^{\mathbf{2}}$ \\
\hline CUPRAC & $1-50$ & $\mathrm{y}=0,0396 \mathrm{x}+0,0953$ & $4 \times 10^{-4}$ & $7 \times 10^{-5}$ & 0,9931 \\
\hline
\end{tabular}

ÇA: çalışma aralığı, a:6 kalibasyon eğrisi, LR: lineer regresyon, Sa: regresyon eğrisindeki kaymanın standart sapması Sb: regresyon eğrisindeki eğimin standart sapması, R2: korelasyon katsayısı

Tablo 2. Ortalama eşdeğer gallik asit miktarları

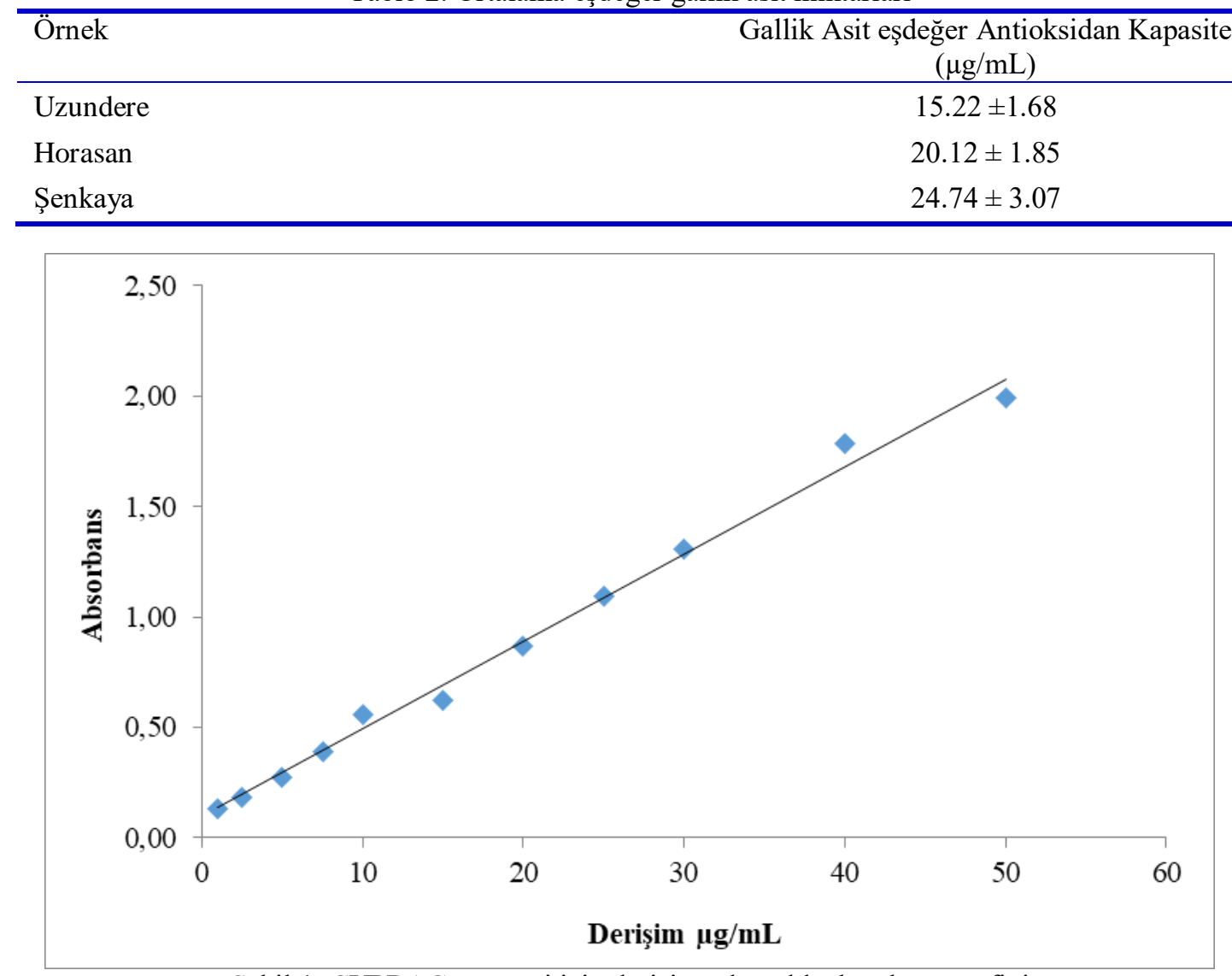

Şekil 1. CUPRAC yöntemi için derişime karşılık absorbans grafiği

\subsection{FRAP Yöntemi}

Çalışmada referans olarak Gallik asit kullanıldı. Derişime karşı absorbans grafiğinin çizgisel olarak belirlendiği 1-30 $\mu \mathrm{g} / \mathrm{mL}$ çalışma aralığında kalibrasyon eğrisi çizildi (Şekil 2) ve istatistiksel açıdan değerlendirildi (Tablo 3). Daha sonra Huş ağacı numuneleri aynı şekilde ölçüldü ve Gallik asit eşdeğer antioksidan kapasiteleri hesaplandı. Ortalama eşdeğer Gallik Asit miktarları Tablo 4’te verildi.

Tablo 3. Kalibrasyon eğrisinin istatistiki değerleri

\begin{tabular}{cccccc}
\hline Yöntem & $\begin{array}{c}\text { ÇA } \\
(\mu \mathbf{g} / \mathbf{m L})\end{array}$ & $\mathbf{L R}^{\mathbf{a}}$ & Sa & Sb & $\mathbf{R}^{\mathbf{2}}$ \\
\hline FRAP & $1-30$ & $\mathrm{y}=0,0282 \mathrm{x}+0,0161$ & $4 \times 10^{-4}$ & $7 \times 10^{-5}$ & 0,9975
\end{tabular}

ÇA: çalışma aralığı, a:6 kalibasyon eğrisi, LR: lineer regresyon, Sa: regresyon eğrisindeki kaymanın standart sapması Sb: regresyon eğrisindeki eğimin standart sapması, R2: korelasyon katsayısı

Tablo 4. Ortalama eşdeğer gallik asit miktarları

\begin{tabular}{cc}
\hline Örnek & Gallik Asit eşdeğer Antioksidan Kapasite $(\boldsymbol{\mu g} / \mathbf{m L})$ \\
\hline Uzundere & $8.48 \pm 0.47$ \\
\hline Horasan & $11.18 \pm 0.44$ \\
\hline Şenkaya & $11.80 \pm 0.25$ \\
\hline
\end{tabular}




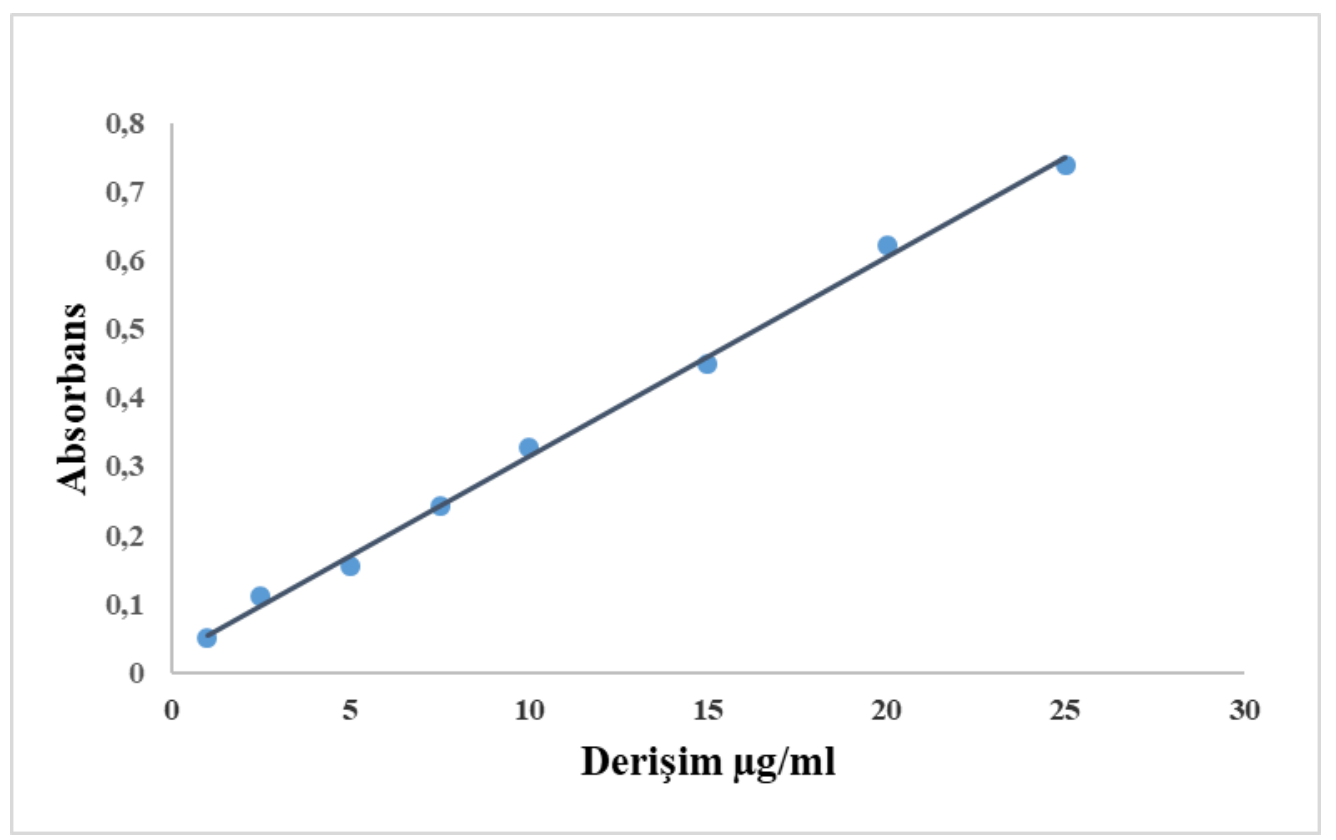

Şekil 2. FRAP yöntemi için Derişime karş1lık absorbans grafiği

\subsection{DPPH Yöntemi}

Deney prosedürüne göre; farklı konsantrasyonda Gallik asit numuneleri 30 dakika boyunca beklemeye bırakılmıştır ve bu inkübasyon evresinden sonra $515 \mathrm{~nm}$ dalga boyunda her bir numunenin ölçümleri yapılmıştır. Kontrol numunesi olarak Gallik Asit kullanılmışır. 1-20 $\mu \mathrm{g} / \mathrm{mL}$ çalışma aralı̆̆ının derişime karşı absorbans grafiğinin lineer olduğu kalibrasyon eğrileri bulunmuştur (Şekil 3) ve bunların hesaplamaları istatistiksel olarak yapılmıştır (Tablo 5). Huş ağacı numunelerinden 6'şar örnek olacak şekilde aynı yöntem ile ölçümler gerçekleştirilmiş̧tir. Gallik asit eşdeğer antioksidan kapasiteleri kayıt altına alınmıştır. Ortalama Gallik asit eşdeğer inhibisyon miktarları Tablo 6'da gösterilmiştir.

Tablo 5. Kalibrasyon eğrisinin istatistiki değerleri

\begin{tabular}{|c|c|c|c|c|}
\hline Yöntem & $\begin{array}{c}\text { ÇA } \\
(\mu \mathrm{g} / \mathrm{mL})\end{array}$ & LRa & $\mathbf{S b}$ & $\overline{\mathbf{R}^{2}}$ \\
\hline$\overline{\mathrm{DPPH}}$ & $1-20$ & $y=4.9479 x-1.389$ & $4 \times 10^{-4}$ & 0.9964 \\
\hline \multicolumn{5}{|c|}{$\begin{array}{l}\text { ÇA: çalışma aralı̆̆ } \text {, a:6 kalibasyon eğrisi, LR: lineer regresyon, Sa: regresyon eğrisindeki kaymanın standart sapması Sb: regresyo } \\
\text { eğrisindeki eğimin standart sapması, R2: korelasyon katsayısı }\end{array}$} \\
\hline Örnek & & Gallik & ğer Antioksidan Kapas & $/ \mathrm{mL})$ \\
\hline Uzundere & & & $4.50 \pm 0.32$ & \\
\hline Horasan & & & $6.48 \pm 0.29$ & \\
\hline Şenkaya & & & $7.20 \pm 0.24$ & \\
\hline
\end{tabular}




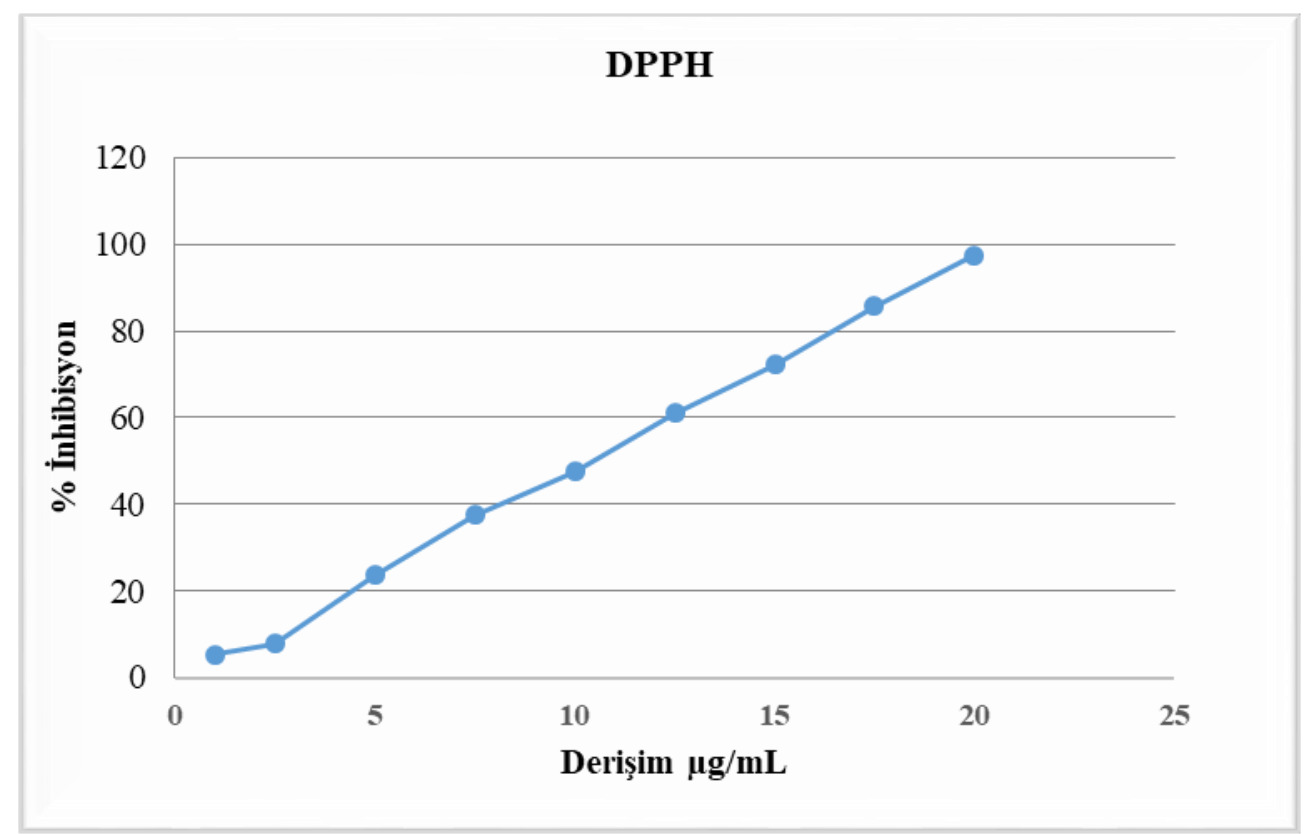

Şekil 3. DPPH Yöntemi için Derişime karşlık absorbans grafiği

\subsection{Kemometrik Analiz}

Varyans matrisinin çözülmesiyle elde edilen skor grafiği Şekil 4'de verilmiştir.

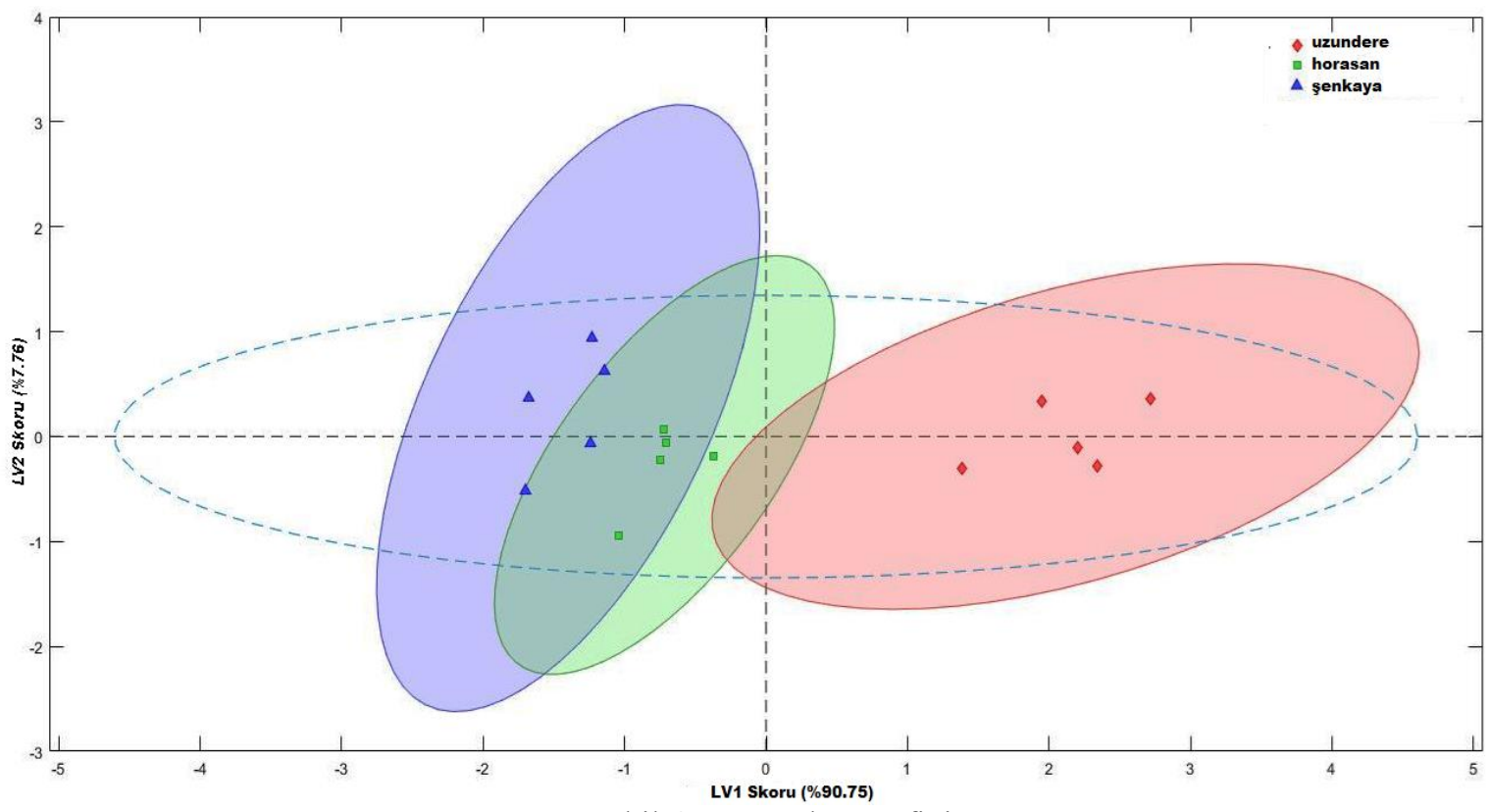

Şekil 4. OPLS skor grafiğii.

Yapılan ölçüm modelin \%98.51'ini açıklamıştır ve başarılı bir kümeleme işlemi gerçekleştirilmiştir. Farklı örneklerin arasında bölgelere göre istatistiksel olarak anlamlı farklar tespit edilmiştir.

Ward's yöntemine göre yapılan hiyerarşik kümeleme analizi de coğrafi bölgeler arasındaki farkı net bir şekilde ortaya koymuştur. Ward's kümeleme yöntemi, kümeler arası uzaklı̆̆ın tespiti için varyans değerlerini yani her bir örneğin küme merkezine olan uzaklı̆̆ını esas alır. Bu yöntemin temel amacı her bir küme içi kareler toplamını minimize etmektir. Bu sayede kümeler içi kareler toplamının minimize edildiği optimum sayıda kümeyi belirler ve elde edilen skorları şematize eder. Örneklerin analizi sonucu elde edilen dendogram Şekil 5 'de sunulmuştur. 


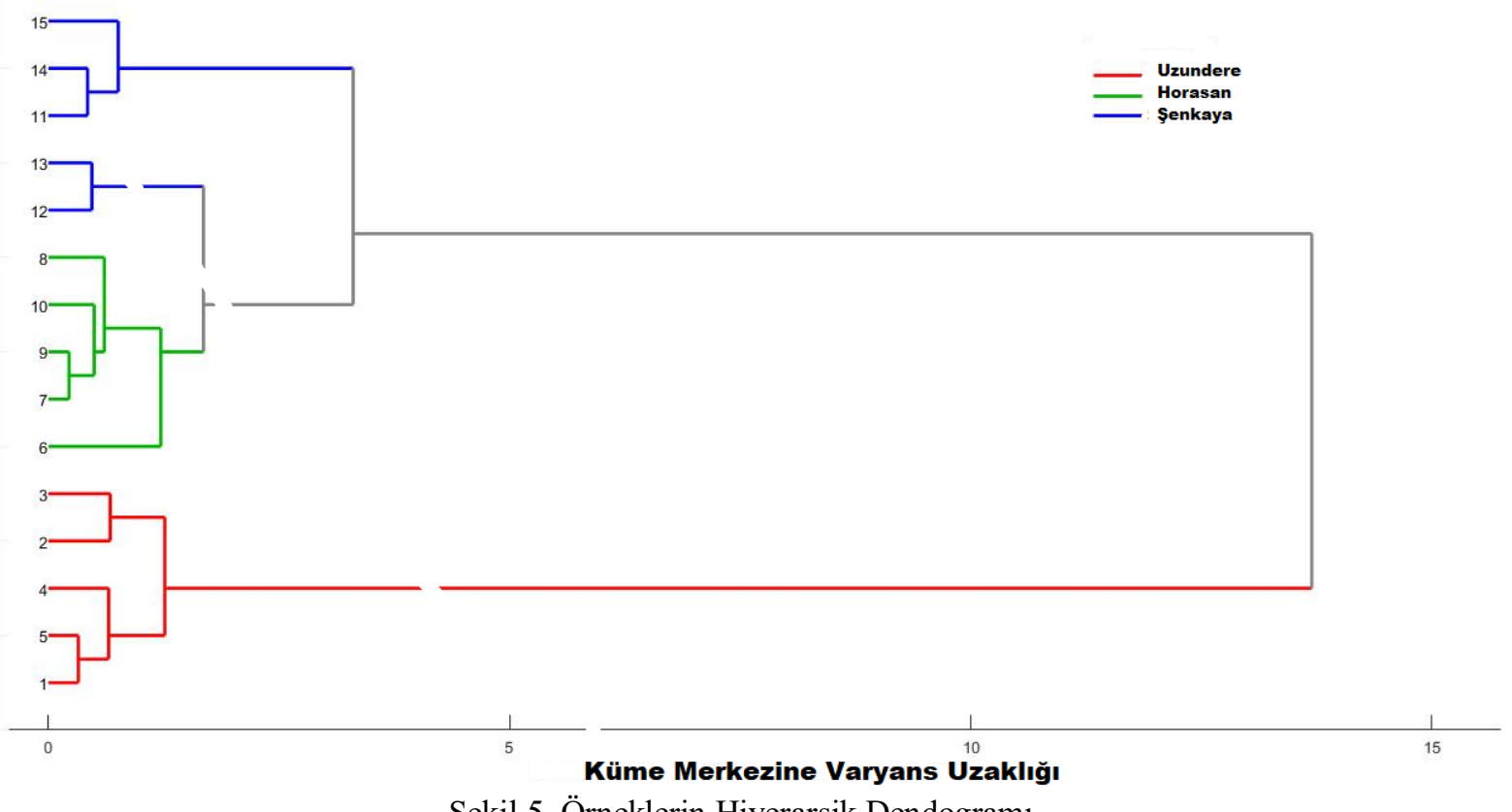

Şekil 5. Örneklerin Hiyerarşik Dendogramı

\section{Sonuç ve Öneriler}

Yapılan çalışmada ticari önemi olan ve Doğu Anadolu bölgesinin sık görülen türlerinden biri olan Huş Ağacının farklı coğrafi bölgelerden toplanan yapraklarının etanol ekstreleri incelenmiş ve antioksidan seviyelerine göre coğrafi farklılıkların etkisi belirlenmiştir. Bütün örneklerin antioksidan kapasite gösterdiği in vitro deneylerle onaylanmıştır. Bütün örnekler kapasite radikallerine olumlu sinyal vermiştir.

Yapılan çalışmada Huş ağacı için en yüksek antioksidan kapasite Şenkaya bölgesinden alınan örneklerde saptanmıştır. Elde edilen bulgulara göre antioksidan kapasitenin rakım ile değişkenlik gösterebileceği sonucuna varılmıştır. Yapılan birçok çalışmada rakımın fenolik bileşikleri artırabileceği ve antioksidan içeriğe olumlu katkı yapabileceği belirtilmiştir (Chan vd., 2007; Lachman vd., 2008; Guo vd., 2011; Wang vd., 2014). Bu yönüyle yaptığımız çalışma literatürle uyumludur.

Güncel çalışmalara bakıldığında betula cinsi ağaç yapraklarında antioksidan kapasite tayini DPPH (Costea vd., 2016), ABTS (Mashentseva vd., 2011) ve FRAP (Azman vd., 2017) yöntemleriyle tayin edilmiş ve orta düzey antioksidan kapasite gösterdiği tespit edilmiştir. Çalışmamız kemometrik algoritmaların kullanıldığı ve CUPRAC antioksidan kapasite yönteminin bu örnekler üzerinde uygulandığ 1 ilk çalışmadır. Rakım ile antioksidan kapasite ilişkisinin incelendiği ilk çalışma olması nedeniyle de özgündür.

Huş ağaçlarının özellikle Şenkaya bölgesinde yetişen yapraklarında yüksek antioksidan kapasite tespit edilmesi bu bitkinin fenolik yönden zengin olduğu ve kanser, kozmetik, erken yaşlanma ürünleri ve bunun gibi serbest radikallerle ilgili yapılan çalışmalarda kullanılabileceğini göstermektedir. Bununla birlikte yapılan kemometrik modelleme çalışmasının coğrafi karakterizasyonda antioksidan kapasite ölçüm yöntemlerinin güvenilir bir parametre olarak kullanılabileceği sonucuna varılmıştır.

\section{Kaynaklar}

1. Azman NAM, Skowyra M, Muhammad K, Gallego MG, Almajano MP (2017). Evaluation of the antioxidant activity of Betula pendula leaves extract and its effects on model foods. Pharmaceutical biology, 55(1), 912-919.

2. Atkinson M (1992). Betula pendula Roth (B. verrucosa Ehrh.) and B. pubescens Ehrh, Journal of Ecology, Vol. 80, 837-870

3. Bonina FP, Puglia C, Frasca G, Cimino F, Trombetta D, Tringali G, Roccazzello A, Insiriello E, Rapisarda P, Saija A (2008). Protective effects of a standardised red orange extract on air pollutioninduced oxidative damage in traffic police officers. Natural Product Research, Vol. 22, 1544-1551. 
4. Bono R, Tassinari R, Bellisario V, Gilli G, Pazzi M, Pirro V, Mengozzi G, Bugiani M, Piccioni P (2015). Urban air and tobacco smoke as conditions that increase the risk of oxidative stress and respiratory response in youth. Environmental Research, Vol. 137, 141-146.

5. Bursal E, Güzel E, Remzi B (2013). Çiriş otunun (Asphodelus aestivus) antioksidan kapasitesinin belirlenmesi. Muş Alparslan Üniversitesi Fen Bilimleri Dergisi, 1.

6. Calderon-Garciduenas L (2016). Smoking and Cerebral Oxidative Stress and Air Pollution: A Dreadful Equation with Particulate Matter Involved and One More Powerful Reason Not to Smoke Anything! Journal of Alzheimers Disease, Vol. 54, 109-112.

7. Chan EWC, Lim YY, Chew Y (2007). Antioxidant activity of Camellia sinensis leaves and tea from a lowland plantation in Malaysia. Food chemistry, Vol. 102, 1214-1222.

8. Codoñer-Franch P, Valls-Bellés V, Arilla-Codoñer A, Alonso-Iglesias E (2011). Oxidant mechanisms in childhood obesity: the link between inflammation and oxidative stress. Translational Research, Vol. 158, 369-384.

9. Costea T, Vlase L, Ancuceanu RV, Dinu M, Olah NK, Popescu ML, Gird CE (2016). Chemical Composition, Antioxidant Activity and Phytotoxic Properties of Silver Birch Leaves. Romanian Biotechnological Letters, 21(3).

10. D Archivio M, Filesi C, Di Benedetto R, Gargiulo R, Giovannini C, Masella R, (2007). Polyphenols, dietary sources and bioavailability. Annali-Istituto Superiore di Sanita, Vol. 43, 348.

11. DOĞMUŞ D, DURUCASU İ (2013). Keten tohumu çeşitlerinin n-bütanol fraksiyonlarının fenolik bileşenlerinin antioksidan kapasitesi. Celal Bayar University Journal of Science, 9.

12. Duthie GG, Duthie SJ, Kyle JA (2000). Plant polyphenols in cancer and heart disease: implications as nutritional antioxidants. Nutrition research reviews, Vol. 13, 79-106.

13. Guo XD, Ma YJ, Parry J, Gao JM, Yu LL, Wang M (2011). Phenolics content and antioxidant activity of tartary buckwheat from different locations. Molecules, Vol. 16, 9850-9867.

14. Güner S, Zengin G, Aktümsek A (2014). Acanthus Hirsutus'un Aseton Özütünün Antioksidan Özelliklerinin Araştırılması. Selçuk Üniversitesi Fen Fakültesi Fen Dergisi, 1-9.

15. Keinänen M, Julkunen-Tiitto $\mathbf{R}$ (1998). High-performance liquid chromatographic determination of flavonoids in Betula pendula and Betula pubescens leaves. Journal of Chromatography A, Vol. 793, 370377.

16. Lachman J, Hamouz K, Orsák M, Pivec V, Dvořák, P (2008). The influence of flesh colour and growing locality on polyphenolic content and antioxidant activity in potatoes. Scientia Horticulturae, Vol. 117, 109114.

17. Mashentseva AA, Dehaen W, Seitembetov TS, Seitembetova AJ (2011). Comparison of the antioxidant activity of the different Betula pendula Roth. extracts from northern Kazakhstan. Journal of Phytology, Vol. 3

18. Moller P, Wallin H, Knudsen LE (1996). Oxidative stress associated with exercise, psychological stress and life-style factors. Chemico-Biological Interactions, Vol. 102, 17-36.

19. Pääkkönen E, Holopainen T, Kärenlampi L (1997). Variation in ozone sensitivity among clones of Betula pendula and Betula pubescens. Environmental Pollution, Vol. 95, 37-44.

20. Pacifici RE, Davies KJ (1991). Protein, lipid and DNA repair systems in oxidative stress: the free-radical theory of aging revisited. Gerontology, Vol 37, 166-180.

21. Pawłowska L (1983). Biochemical and systematic study of the genus Betula L. Acta Societatis Botanicorum Poloniae, Vol 52, 301-314.

22. Sarikürkcü C, Cengiz M, Çomak Z, Zengin G, Aktümsek A (2016). İki Ononis Türünün Antioksidan Kapasitelerinin Karşılaştırılması. Süleyman Demirel Üniversitesi Fen Bilimleri Enstitüsü Dergisi, Vol 1, 20.

23. Shetty A, Magadum S, Managanvi K (2013). Vegetables as sources of antioxidants. J Food Nutr Disorder, Vol 2, 1-2

24. Velioğlu S (2000) Doğal antioksidanların insan sağlığına etkileri. GIDA/THE JOURNAL OF FOOD, 25.

25. Wagner H, Tittel G, Bladt S (1983). Analysis and standardization of medicinal plant materials by high performance liquid chromatography and other chromatographic methods. Deutsche Apotheker Zeitung, Vol $123,515-521$.

26. Wang LJ, Su S, Wu J, Du H, Li SS, Huo JW, Zhang Y, Wang LS (2014). Variation of anthocyanins and flavonols in Vaccinium uliginosum berry in Lesser Khingan Mountains and its antioxidant activity. Food chemistry, Vol 160, 357-364. 